\title{
Academic cooperation in family medicine: A viewpoint from Split
}

\begin{abstract}
University of Split School of Medicine Department of Family Medicine Split, Croatia

Corresponding author: Mirjana Rumboldt

Lovretska 1

21000 Split

Croatia

mirjana.rumboldt@mefst.hr

Tel.: + 38521319833

Fax.: + 38521465304

Received: 24 June 2013

Accepted: 19 December 2013

Copyright (c) 2014 by

Academy of Sciences and Arts

of Bosnia and Herzegovina.

E-mail for permission to publish:

\author{
Mirjana Rumboldt, Dragomir Petric
}

amabih@anubih.ba

\section{Introduction}

More than a century has elapsed since Abraham Flexner, a renowned educator and descendant from a physicians' family, radically influenced the concept and structure of medical education with his report on the poor condition of medical schools in North America (1). The basic tenets of a good medical school, which had to incorporate not just teaching, but also a trinity of scientific investigation, health services, and education of future medical professionals, were set. This approach marked a turning point in the concept of medical education worldwide. These principles apply to all components of a medical school, including family medicine (FM).

As a professional league, FM is very numerous (for instance, in Croatia, with about 4.4 million inhabitants, there are 2,345 family physicians or a ratio of about 1:1900 inhabitants), while as an academic discipline it is tiny and understaffed. Indeed, four FM chairs in this country have just 18 faculty members ( 9 professors and 9 associate professors). Although FM is the most numerous in terms of practitioners, its educators are few and far between. By comparison there are 1225 general internists and 248 of them are faculty members (with 57 professors and 
49 associate professors).This disproportion may be due to several factors. In particular there is a negative selection; hospital residencies are preferred, and FM specialization is not mandatory for FM practice in Croatia. Consequently, a number of FM practitioners in Croatia are not specialist/consultants in the field (1151 out of 2345 or $49.1 \%$ ) and are therefore practically banned from scholarship/faculty election. Moreover, current capitation, a counterproductive way of financing primary care, stimulates agglomeration of health care beneficiaries (patients) with decreasing quality of care due to lack of time and space. All that may be summarized in two opposite trends: shortage (in motivation, proficiency, scholarship, practice-academia interaction) and surplus (in overbooked visits, administrative, financial and organizational burdens, isolation, and substandard office equipment). Nevertheless, a study across Croatia has shown that FM practitioners have a highly affirmative attitude towards medical science (about 80\% gave very positive answers) and scientific/ professional literature (over 90\%). However, their publication activity was low (papers referred to in Index Medicus have authored $6 \%$, and in Current Contents just 1.6\% of them) (2). As academic involvement is a mainstay of publication, increasing of this process to match FM support of scholarly activity will necessarily involve research and scientific education.

The aim of this short review is to present the current status of cooperation between the academic departments of Family Medicine in the region as seen at the Split department, and to outline opportunities for improvement.

\section{Department of Family medicine in Split University School of Medicine}

The Split chair of family medicine sprouted from the Zagreb alma mater in 1976, and became an independent department in 1997 with the establishment of the Split University School of Medicine, the first graduate school founded in the independent Republic of Croatia. It has a peculiar undergraduate curriculum of 180 teaching hours per student (100 hours of practice, particularly on the islands and in the rural areas of the Dalmatian Highland consisting of autonomous work under tutorial supervision; 60 hours of seminars with case presentations or role playing; and 20 hours of interactive lecturing).

At the time of its constitution, the Split department of FM consisted of only one associate professor and six assistants, three of them with a MB degree, and some 20 practice tutors (their number varied according to the number of enrolled students, since each tutor/mentor could accept no more than two of them in the office). Summative exams were composite from the beginning (a multiple choice written test, patient consultation in the tutor's office, and oral examinations with pulling of announced questions). Our parent chair and its staff from Zagreb was initially of invaluable help in the teaching process and in the summative students' assessments.

After some years, a visiting professor in FM from the Ljubljana School of Medicine (Slovenia) was elected in 2007 (3) and continues to lecture here today. The teaching subjects and contents were permanently accommodated to current practice issues (e.g. controversies in the management of hyperlipidemia or diabetes mellitus type 2 ) or sociomedical problems (e.g. patients' rights, family violence, bullying). The freshmen, in their first study year, were already exposed to the FM perspective within the subject "Introduction to medicine" (25 hours, since 1997). Student polls consistently rated this course as highly appreciated. Unfortunately, the subject was truncated in 2009. Some improvements have been incorporated in the FM curriculum, particularly in the summa- 
tive part of the FM examination, since the tutorial assessment was not reliable enough; instead of this, OSCE (Objective Structured Clinical Examination) was introduced in 2010. For its sake a practicum of clinical skills was published in 2012 (4). Several dolls and models for OSCE were borrowed from the Mostar University School of Medicine since its FM department introduced this kind of practical examination in 2009. In addition, as a part of the exam letters to the patient (5) and PEARLS (Practical Evidence About Real Life Situations and/or Presenting Evidence Abstracted from the Research Literature for the Solution of real patient's problems) were introduced (6).

Scientific advancement and scholarly achievements were occurring at a much slower pace, presumably due to the age of the assistants (mean around 48 years) and the just started, detrimental FM privatization/leasing (from 1998; formerly all FM practitioners were community health center employees), which forced doctors to devote time to business practice instead of medicine. The department has slowly rejuvenated over the past ten years, first with the admission of two assistants (one with the MB degree), and later with two novices on the international INTER HEART 2 project, animating scientific publication, thesis and dissertation defense, and scholarly progress (3). Today the Department has one professor, two associate professors, three $\mathrm{PhDs}$, two senior lecturers, five assistants, and six practice tutors (the number of the latter is variable, according to the number of enrolled students).

\section{International and interfaculty cooperation}

This collaboration, both at the national and international level, depends on mutuality in the fields of scientific endeavor, patient care services, and education of future doctors (Table 1).

The opportunities at the international level, e.g. EGPRN (European General Practice Research Network), EURACT (European Academy of Teachers in General Practice) or WONCA Europe, are underutilized. Regional interdepartmental synergy remains low (Figure 1).

The Slovenian chairs from Ljubljana and Maribor are unique, having developed successful interaction not only with Croatia, but also with Bosnia and Herzegovina, Macedonia, Montenegro, and Serbia $(7,8)$.

Our department has established good links with Bosnia and Herzegovina (mostly with Mostar, less with Sarajevo) in terms of

Table 1 Opportunities for interfaculty cooperation

\begin{tabular}{|c|c|c|c|}
\hline \multirow{2}{*}{ Science } & \multicolumn{2}{|l|}{ Education } & \multirow{2}{*}{ Profession } \\
\hline & Undergraduate & Postgraduate & \\
\hline $\begin{array}{l}\text { Mentoring, coaching } \\
\text { young researchers }\end{array}$ & $\begin{array}{l}\text { Student exchange (e.g. Erasmus, } \\
\text { practice groups) }\end{array}$ & $\begin{array}{l}\text { Targeted meetings (e.g. } \\
\text { DNOOM }^{* *} \text { ) }\end{array}$ & $\begin{array}{l}\text { Mutual evaluation of new } \\
\text { technologies }\end{array}$ \\
\hline $\begin{array}{l}\text { Joint scientific boards, } \\
\text { guideline committees }\end{array}$ & $\begin{array}{l}\text { Reciprocation in teaching aids and } \\
\text { summative assessment techniques }\end{array}$ & $\begin{array}{l}\text { Harmonization of } \\
\text { curricula }\end{array}$ & $\begin{array}{l}\text { Synchronized legislative } \\
\text { proposals }\end{array}$ \\
\hline
\end{tabular}

*HUOM: Croatian Society of Family Medicine; **DNOOM: Association of Teachers in General and Family Medicine. 


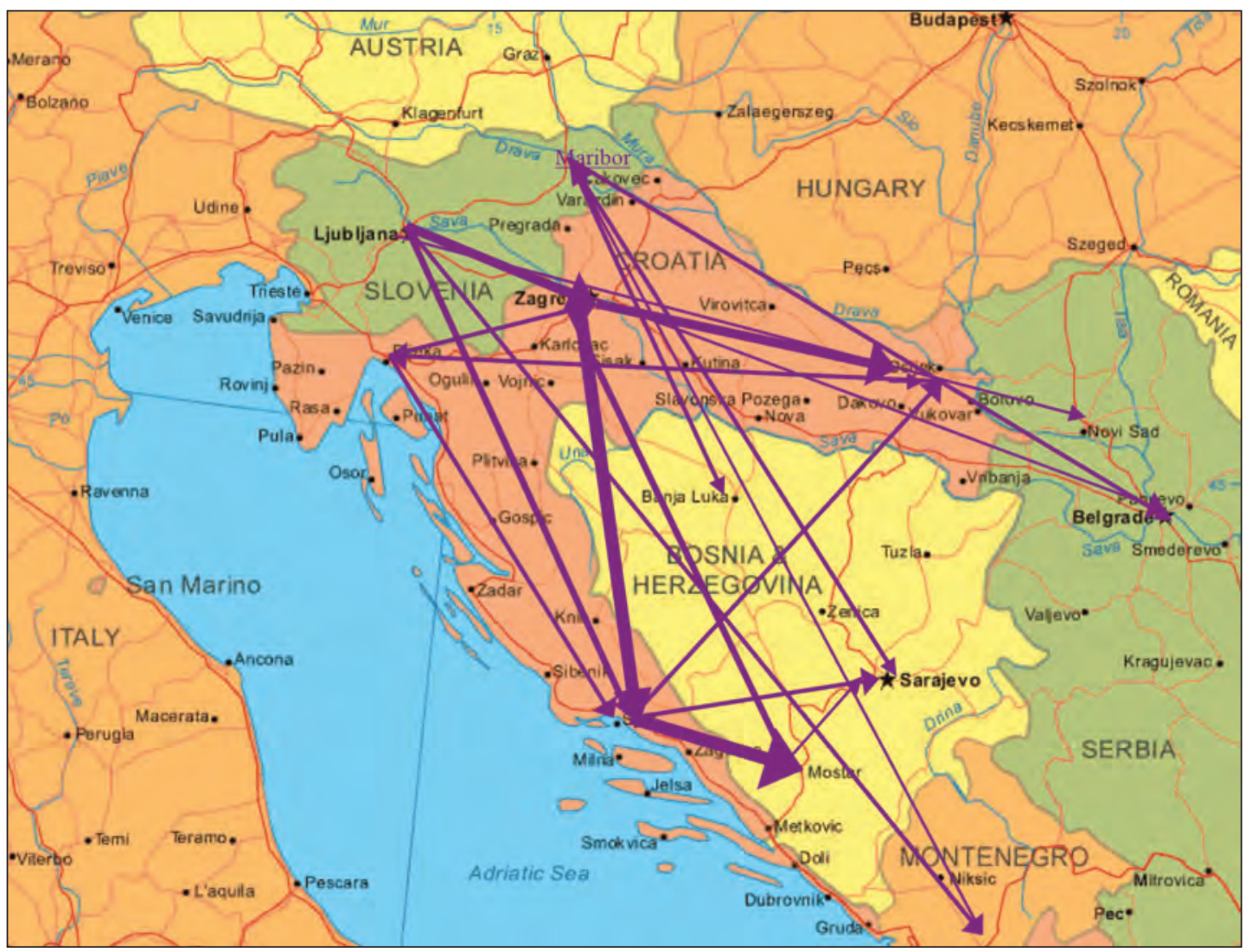

Figure 1 Bidirectional arrows on the chart show the actual interfaculty cooperation in this part of Southern Europe. Thicker arrows indicate higher intensity of collaboration. Links between Zagreb (Croatia), Maribor and Ljubljana (Slovenia) with Skopje (Macedonia) are not shown for graphic reasons.

lecturing, summative exams, coaching/mentoring of term papers ( $\mathrm{MB}, \mathrm{PhD}$ theses), and continues its relationships with Zagreb and Ljubljana.

Slovenian colleagues, in addition to one visiting professor, have contributed with their authorship to our recent FM textbook (9).

Although most departments are deeply interested in collaboration, at least declaratively, it is seldom materialized in practice, and when implemented it is often in a unidirectional way.

Some efforts towards international cooperation have been done. In particular the chairs in Maribor, Mostar, Ljubljana, Zagreb, and Split are striving to invigorate these relationships. Cooperation must be a two-way street, i.e. mutual: all the par- ticipants must profit. Currently, there are several obstacles on this path, such as inadequate infrastructure, geographic remoteness, an unfavorable economic situation in some regions with repercussions on their medical schools, and understaffed academic departments. Synergy between our chairs in these circumstances can not be perfectly balanced and bidirectional; it is understandable and almost mandatory that "stronger" chairs help the "weaker" ones until their material base and scholarship matures (examples are Zagreb - Split, Split - Mostar, and Ljubljana - Podgorica, Montenegro). Nevertheless, the departments in Ljubljana and Zagreb are currently preparing a common FM textbook.

As an academic discipline we are not flamboyant; individually we are weak, even 
at the level of our medical schools by virtue of our low numbers in academia. United we may instigate a number of relevant, multicentric, and complementary clinical studies, promote academic achievements of our colleagues, and enhance the appropriateness and efficiency of primary health care. Publication in peer reviewed journals must also be stimulated, including the local periodicals (e.g. Medicina Familiaris Croatica is regularly published since 1992 , with two issues per year).

The study of medicine has recently regained its appeal, and the number of young people eager to become doctors is anticipated to increase, especially in our region, which will expand the need for medical teachers (moreover, there are studies in English at Zagreb and Split Medical Schools). The emphasis on health care, not only in the region but worldwide, is moving from hospital and specialist towards primary care and family medicine because it is more effective, less expensive, and hence more sustainable (10). Especially important are the issues of primary care management and comprehensive approach; person-centered care, holistic approach and community orientation are the future of medicine and the province of FM.

\section{Conclusion}

We recommend the following specifics to achieve our goals:

1. Scientific research. Focus on clinical and epidemiological studies, particularly concerning quality of life and preventive activities, aimed at clinically relevant outcomes (PCOR, i.e. Patient-Centered Outcomes Research) (11). These can be done at the student level as part of their core curriculum, and can be supported by practitioners mentoring these students. Consider formally studying the following current issues within our community, all easily investigated within our patient population:
- effectiveness and risk/benefit evaluation of prescribing allopurinol vs. placebo to asymptomatic hyperuricemic patients (acute attacks, tophi, atherosclerotic, especially coronary heart disease) (12); effects of vitamin C (13), cherries (14), and their combination on uric acid levels and incidence of acute gouty attacks;

- clinical effectiveness of chondroitin sulphate, glucosamine, their combination, or placebo on knee osteoarthritis managed with the optimal standard therapy (15);

- impact of PSA screening for prostate cancer in primary care on the survival of male middle-aged patients (16);

- effectiveness of antibiotic treatment (amoxicillin + clavulanic acid) for patients with low back pain lasting over 6 months (17).

2. Medical education. Continue to improve and harmonize the undergraduate and postgraduate teaching process $(18,19)$ in cooperation with international FM organizations, such as the mentioned EURACT in Europe or STFM (Society of Teachers of Family Medicine) in the USA. Consider the following attempts:

- exchange of experience with the existing and/or novel teaching aids; weighing the reasons for and against their routine implementation;

- balancing and updating the catalogues of skills, knowledge, and attitudes sought and taught within our medical schools;

improving specific problem solving competency through formal study of how to solve clinical problems and testing these skills in an OSCE environment (e.g. decision making skills, management of comorbidity/multimorbidity);

- coordination of examination criteria for undergraduate and postgraduate studies; comparison of the existing summative assessment programs (Table 2). 
Table 2 Scoring at the undergraduate FM examination in Split, academic year 2012/13

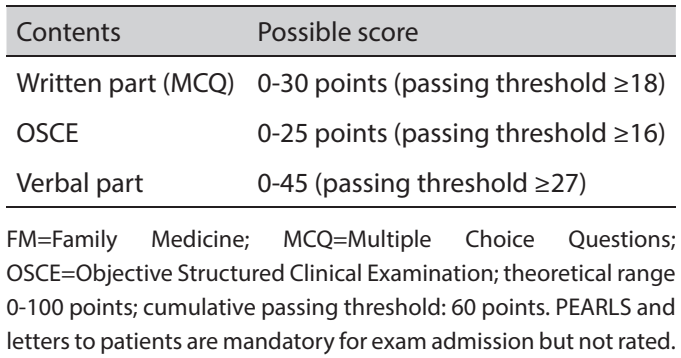

3. Professional issues. Improvement in competencies and social rating of family physicians $(6,18)$. In particular improving the perception of FM by other specialists by: - setting FM guidelines for some imaging (e.g. CT or MR) referrals or for the prescription of some outpatient medications, which are mainly relegated to a narrow spectrum of specialists or subspecialists with no clear scientific, economic or professional grounds;

- harmonization of guidelines for referral to consultant specialists;

- proposing the minimal equipment for a FM office (e.g. minor surgery set, otoscope etc.), indicating the desirable equipment (e.g. ultrasound, ECG etc.), and stressing the needless ones (e.g. bone densitometer, $\mathrm{x}$-rays machine etc.).

Working together we have the ability to overcome our challenges and improve outcomes for our patients, while increasing interest in FM and improving the quality of our practices.

Authors' contributions: Conception and design: MR,DP; Acquisition, analysis and interpretation of data: MR, DP; Drafting the article: MR; Revising it critically for important intellectual content: MR, DP.

Conflict of interest: The authors declare that they have no conflict of interest.

\section{References}

1. Flexner A. Medical education in the United States and Canada. A report to the Carnegie foundation for the advancement of teaching. Bulletin 4. New York: Carnegie Foundation; 1910.

2. Mrdeša-Rogulj Z. Correlation of attitudes toward science and clinical investigation among family physicians with their abilities to diagnose and manage arterial hypertension and diabetes mellitus [in Croatian]. MB thesis. Split: Split University School of Medicine; 2007.

3. Rumboldt M. Department of family medicine. In: Janković S, Boban M, editors. Medical School in Split, 1997 - 2007 [in Croatian]. Split: MFS; 2007. p. 281-7.

4. Rumboldt M, editor. OSCE. A practicum of skills for students and residents in family medicine [in Croatian]. Split: Redak; 2012. p. 1-118.

5. Mrduljaš-Đujić N, Pavličević I, Marušić A, Marušić M. Students' letters to patients as a part of education in family medicine. Acta Med Acad. 2012;41:52-8.

6. Vrdoljak D. Teaching evidence based medicine in family medicine. Acta Med Acad. 2012;41:88-92.

7. Klemenc-Ketis Z, Kersnik J. The role of the European Academy of Teachers in General Practice and Family Medicine in family medicine education in Europe - the experience of the University of Maribor. Acta Med Acad. 2012;41:80-7.

8. Kersnik J. A need for an exchange on medical education between FM/GP stakeholders in Europe. Eur J Gen Pract. 2012;18:193-4.

9. Rumboldt M, Petric D, editors. Family medicine selected chapters [in Croatian]. Split: Redak; 2011. p. 1-350.

10. Haggerty JL, Levesque J-F, Hogg W, Wong S. The strength of primary care systems. BMJ. 2013;346:f3777.

11. Roehr B. Research versus the patient. BMJ. 2013;346:f332.

12. Gotsman I, Keren A, Lotan C, Zwas DR. Changes in uric acid levels and allopurinol use in chronic heart failure: association with improved survival. J Card Fail. 2012;18:694-701.

13. Choi HK, Gao X, Curhan G. Vitamin C intake and the risk of gout in men, a prospective study. Arch Intern Med. 2009;169:502-7.

14. Zhang Y, Neogi T, Chen C, Chaisson C, Hunter DJ, Choi HK. Cherry consumption and decreased risk of recurrent gout attacks. Arthritis Rheum. 2012;64:4004-11.

15. Sawitzke AD, Shi H, Finco MF, Dunlop DD, Harris CL, Singer NG, et al. Clinical efficacy and safety of glucosamine, chondroitin sulphate, their combination, celecoxib or placebo taken to treat osteoarthritis of the knee: 2-year results from GAIT. Ann Rheum Dis. 2010;69:1459-64. 
16. Wilt TJ, Ahmed HU. Prostate cancer screening and the management of clinically localized disease. BMJ. 2013;346:f325.

17. Albert HB, Sorensen JS, Christensen BS, Manniche C. Antibiotic treatment in patients with chronic low back pain and vertebral bone edema (Modic type 1 changes): a double-blind random- ized clinical controlled trial of efficacy. Eur Spine J. 2013;22:697-707.

18. Švab I. Possibilities of family medicine in medical education. Acta Med Acad. 2012;41:59-63.

19. Černi Obrdalj E, Curić S, Zalihić A, Rumboldt M. Education in family medicine at the University of Mostar School of Medicine. Acta Med Acad. 2012;41:64-7. 